\title{
The effects of electroporation on viability and quality of in vivo-derived bovine blastocysts
}

\author{
Fuminori TANIHARA ${ }^{1)}$, Maki HIRATA ${ }^{1)}$, Shigeki MORIKAWA ${ }^{2)}$, Nhien Thi NGUYEN1), \\ Quynh Anh LE'), Takayuki HIRANO'), Yoshiyuki FUKUMI'), ${ }^{2}$, shiaki $\mathrm{ABE}^{2)}$ and Takeshige OTOI') \\ 1) Laboratory of Animal Reproduction, Faculty of Bioscience and Bioindustry, Tokushima University, \\ Tokushima 779-3233, Japan \\ 2) Tokushima Prefectural Livestock Research Institute, Tokushima 779-3233, Japan
}

\begin{abstract}
The introduction of exogenous molecules into embryos is required for analyses of molecular dynamics and specific gene functions during early embryonic development. Electroporation is an effective method to transport exogenous molecules into cells, but is rarely used in bovine embryos. First, we evaluated the viability of in vivo-derived bovine blastocysts after electroporation with fluorescein (FAM) labeled-oligonucleotides with varying pulse numbers $(3,5,7$, and 10), while keeping the pulse duration at $1 \mathrm{msec}$ and the electric field of $20 \mathrm{~V} / \mathrm{mm}$. Next, we examined the effects of zona pellucida status on blastocyst quality after electroporation, by comparing the average diameter of blastocysts before and after electroporation using blastocysts with intact zona pellucida and hatching/hatched blastocysts. Electroporation successfully introduced exogenous molecules into in vivo-derived bovine blastocysts without loss of viability. Moreover, the status of the zona pellucida may be associated with the quality of blastocysts after electroporation.
\end{abstract}

Key words: Bovine, Blastocyst, Electroporation, In vivo, Zona pellucida

(J. Reprod. Dev. 65: 475-479, 2019)

D ramatic biological changes during embryonic development, such as gene expression with major embryonic genome activation [1] and epigenetic modifications with DNA methylation and histone modifications [2], have been analyzed in mammals, including cows. In bovine embryos, the methylation status and expression of specific genes in in vitro-developed blastocysts have been studied but suggested to be different from those in in vivo-derived blastocysts [3]. Observing in vivo-derived embryos is required to understand the precise mechanisms of biological changes during early embryonic development. Efficient introduction of exogenous molecules into embryos, such as small interference RNAs (siRNA) for RNA interference [4], morpholinos for disruption of targeted gene function [5], and molecular beacons for imaging specific endogenous RNAs in living cells [6], is required to investigate molecular dynamics and specific gene functions during early embryonic development.

Microinjection is a well-established technique for introducing exogenous molecules into embryos. However, microinjection requires expensive equipment and sophisticated techniques, and the direct insertion and retraction of the needle cause physical stress and mechanical damage to embryos [7-9]. Furthermore, the application of microinjection is generally limited to one- to two-cell stage zygotes/ embryos. Electroporation is another effective and widely used method

Received: April 3, 2019

Accepted: May 30, 2019

Advanced Epub: June 10, 2019

(C)2019 by the Society for Reproduction and Development

Correspondence: M Hirata (e-mail: mhirata@tokushima-u.ac.jp)

This is an open-access article distributed under the terms of the Creative Commons Attribution Non-Commercial No Derivatives (by-nc-nd) License. (CC-BY-NC-ND 4.0: https://creativecommons.org/licenses/by-nc-nd/4.0/) for transporting exogenous molecules into cells [10, 11], and has the potential to be a core technique for efficient introduction of molecules into morula/blastocyst stage embryos, since this is difficult to achieve via microinjection. Recently, electroporation has been applied to introduce exogenous molecules into the zygotes/embryos of mice $[12,13]$, rats [14], and pigs [15], but it is still rarely used in cows. The effects of electroporation-induced damage on the viability of bovine embryos are also unknown.

In this study, we evaluated the viability of in-vivo derived bovine blastocysts after electroporation under different electrical conditions. We used fluorescein (FAM) labeled-oligonucleotides to confirm the successful introduction of molecules. Furthermore, we examined the effects of zona pellucida status on the quality of blastocysts after electroporation by comparing the diameters of blastocysts before and after electroporation.

First, in vivo-derived blastocysts were electroporated with varying numbers of unidirectional pulses $(3,5,7$, and 10$)$, while maintaining the pulse duration at $1 \mathrm{msec}$ and the electric field of $20 \mathrm{~V} / \mathrm{mm}$. A total of 10 blastocysts with intact zona pellucida were electroporated for each pulse number group. After culturing for $24 \mathrm{~h}$, blastocyst viability was assessed microscopically by observation of blastocoel re-expansion. All blastocysts shrank immediately after electroporation in each experimental group but re-expanded after incubation for $24 \mathrm{~h}$ (Fig. 1). The fluorescence from the introduced FAM labeledoligonucleotide was observed in each experimental group immediately after electroporation (Fig. 2). The blastocyst incubated with FAM labeled-oligonucleotide for $5 \mathrm{~min}$ without electroporation and the blastocyst electroporated without FAM labeled-oligonucleotide served as negative controls (Fig. 2).

Next, we performed electroporation (five 1-msec unidirectional 

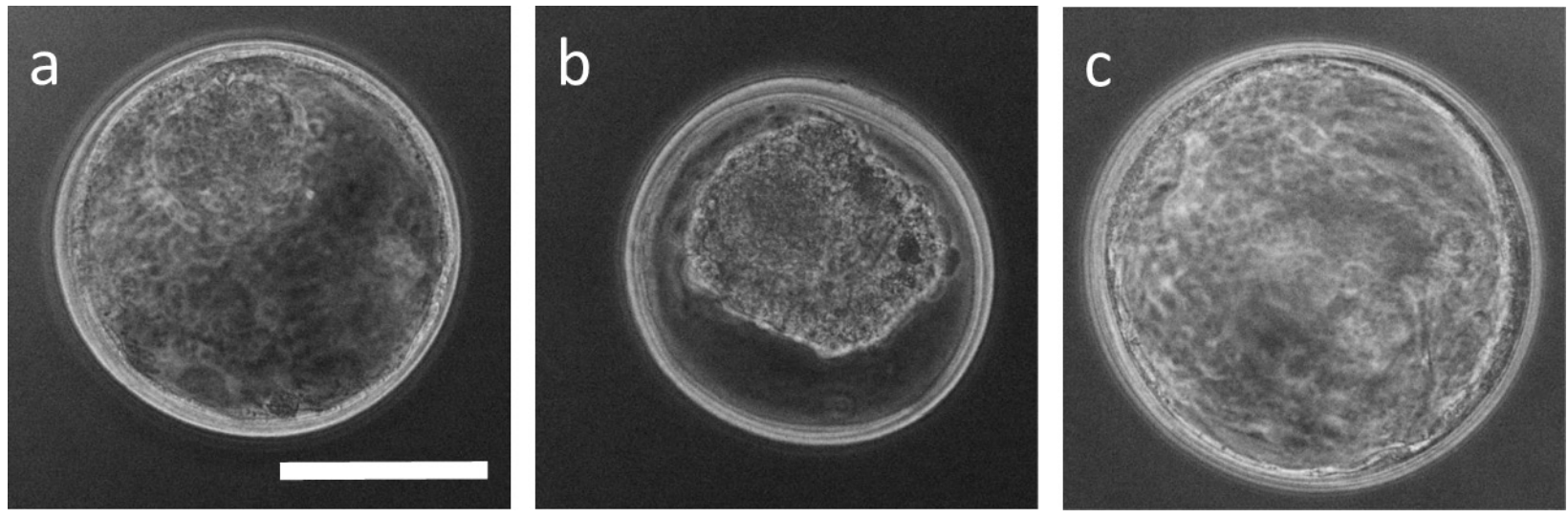

Fig. 1. Representative images of bovine blastocysts. (a) Expanded blastocyst before electroporation. (b) Shrunk blastocyst immediately after electroporation. (c) Re-expanded blastocyst $24 \mathrm{~h}$ after electroporation. Scale bar indicates $100 \mu \mathrm{m}$.
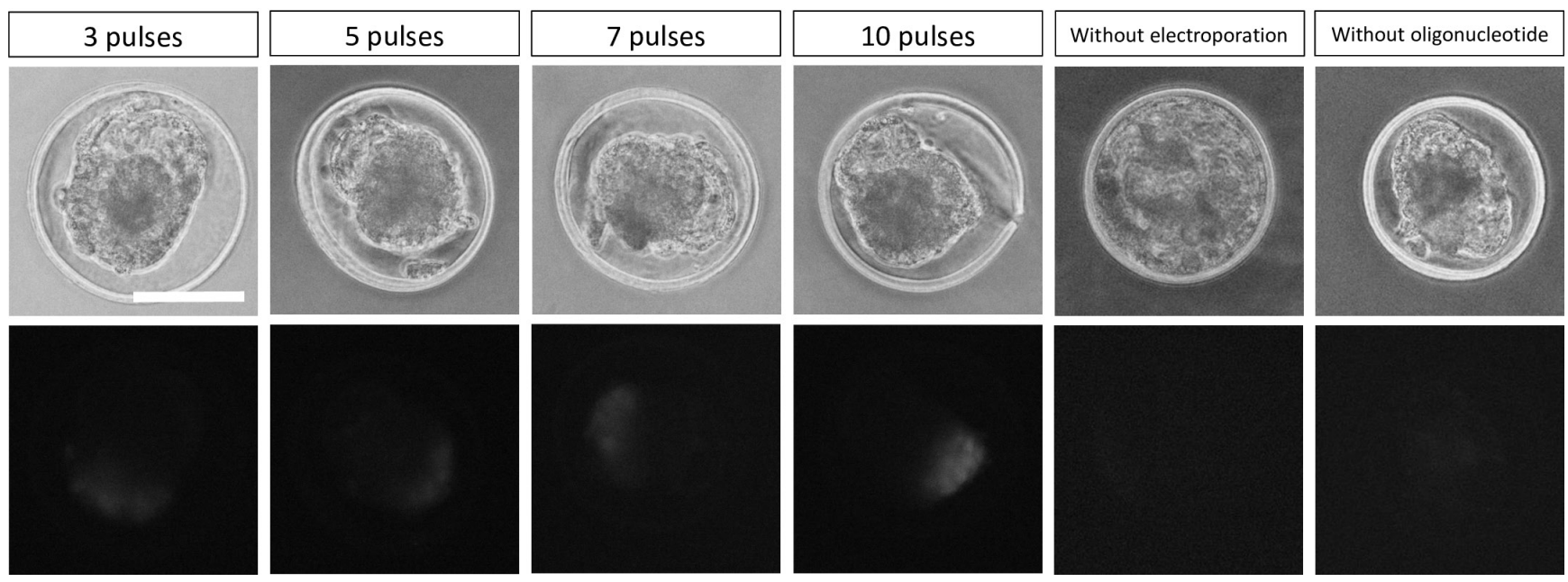

Fig. 2. Representative images of bovine blastocysts after introduction of FAM labeled-oligonucleotide by electroporation with three to ten pulses. Without electroporation: Blastocyst incubated with FAM labeled-oligonucleotide without electroporation as a negative control. Without oligonucleotide: Blastocyst after electroporation without FAM labeled-oligonucleotide as a negative control. Scale bar indicates $100 \mu \mathrm{m}$.

pulses at an electric field of $20 \mathrm{~V} / \mathrm{mm}$ ) to blastocysts with intact zona pellucida, and to blastocysts with partly cracked zona pellucida/ without zona pellucida (hatching/hatched blastocysts). The diameters of blastocysts were measured using ImageJ software (version 1.52a; National Institutes of Health, Bethesda, MD, USA) for both groups before electroporation and $24 \mathrm{~h}$ after electroporation to evaluate the effects of zona pellucida status on the re-expansion of blastocysts. The diameter of each blastocyst was defined as the average of vertical diameter and horizontal diameter excluding the zona pellucida. The average diameter is expressed as mean \pm SEM. The average diameter of blastocysts with intact zona pellucida was comparable before $(170.8 \pm 4.3 \mu \mathrm{m})$ and after electroporation $(178.7 \pm 7.3 \mu \mathrm{m})$. However, the average diameter of hatching/hatched blastocysts after electroporation $(136.5 \pm 9.2 \mu \mathrm{m})$ was significantly lower $(\mathrm{P}<0.01)$ than that before electroporation $(218.7 \pm 10.5 \mu \mathrm{m})$ (Fig. 3).
We evaluated the viability of electroporated in vivo-derived bovine blastocysts by analyzing re-expansion of the blastocoel. In this study, the electroporation conditions were three to ten $1-\mathrm{msec}$ pulses at an electric field of $20 \mathrm{~V} / \mathrm{mm}$. Regardless of the pulse number, all blastocysts with intact zona pellucida re-expanded after electroporation. In mouse in vivo-derived zygotes electroporated by the same electroporation system used in this study, three to seven 3-msec pulses at an electric field of $30 \mathrm{~V} / \mathrm{mm}$ were the optimal conditions under which embryo viability was not significantly affected [16]. These results indicate that in vivo-derived bovine blastocysts may be able to tolerate severe electroporation conditions comparable to the optimal electroporation conditions for mouse zygotes. However, we previously demonstrated that the resistance to electroporation of 1-cell in vitro-derived zygotes in pigs was lower than that in mice [15]. The resistance to electroporation is presumed to be different 


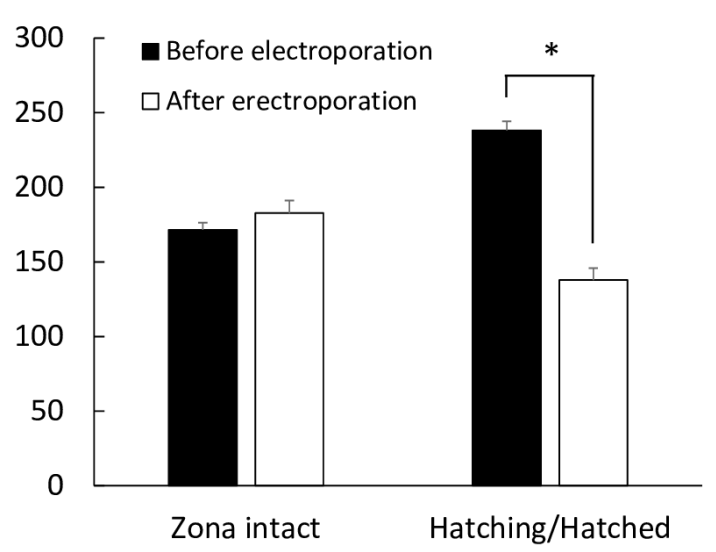

Fig. 3. The average diameter of blastocysts with intact zona pellucida $(\mathrm{n}=12)$ and of hatching/hatched blastocysts $(\mathrm{n}=9)$ before and $24 \mathrm{~h}$ after electroporation. $* \mathrm{P}<0.01$. Error bar, mean $\pm \mathrm{SEM}$.

among animal species. Moreover, in vivo-derived embryos have morphological differences with in vitro-produced embryos [17]. It has been reported that in vitro-produced embryos are more adversely affected by chilling than in vivo-derived embryos [17]. The sensitivity to cooling and freezing is presumed to be related to the relatively higher lipid content often observed in in vitro-produced embryos $[17,18]$. These factors may affect the resistance to electroporation.

Electrofusion of two-cell stage embryos has been reported to be effective for the production of tetraploid blastocysts [19]. Electroporation of bovine embryos after the two-cell stage has the possibility to cause cell fusion. In this study, we did not evaluate cell fusion and polyploidy after electroporation of blastocysts. In general, electrofusion of blastomeres is performed by a single 30-250 $\mu \mathrm{sec}$ pulse at an electric field of $0.50-2.0 \mathrm{kV} / \mathrm{cm}$ [19-21]. In this study, our electroporation condition, 1-msec pulses at an electric field of $20 \mathrm{~V} / \mathrm{mm}$, was longer duration and lower voltage compared to general conditions of electrofusion. The effects of multiple pulses on electrofusion also have not been investigated well. The possibility of electrofusion of two-cell- to blastocyst stage-embryos producing zygotes/embryos during electroporation with multiple pulses with long duration and low voltage requires further investigation.

In this study, the introduction of FAM labeled-oligonucleotide into the blastocyst was achieved. However, a non-homogeneous fluorescence pattern was observed, indicating that some embryonic cells failed to take up the exogenous molecules by electroporation. This non-homogeneous fluorescence pattern is probably caused by the unidirectional electric pulse used in this study, since a bidirectional electric pulse for electroporation is presumed to improve the introduction of exogenous molecules. However, further studies are required because we previously found that the bipolar pulse affects blastocyst formation in porcine in vitro-fertilized zygotes [22]. Recently, the introduction of siRNA into 8-16-cell stage bovine embryos was achieved by the lipofection method after removal of the zone pellucida [23]. The combination of these technologies can be an effective strategy for improving introduction of exogenous molecules into blastocysts. Moreover, cell type is also a possible factor affecting the fluorescence pattern introduced by electroporation. The optimal electroporation conditions for introducing exogenous molecules into cells are specific to cell type [24]. However, to our knowledge, optimal electroporation conditions for cells composing blastocysts, cells of inner cell mass and trophectoderm, have not been investigated. Therefore, further investigations are required.

Next, we demonstrated that the blastocysts with intact zona pellucida were expanded $24 \mathrm{~h}$ after electroporation, of which the average diameter was comparable to that before electroporation. On the other hand, the hatching/hatched blastocysts were shrunk by electroporation and failed to expand to the same degree with before electroporation. These results indicate that the cracking/ existence of the zona pellucida during electroporation affects the quality of blastocysts. In mice, the existence of zona pellucida is one of the factors affecting the viability of electroporated embryos [12]. Therefore, performing electroporation before hatching of zona pellucida can minimize electroporation-induced damages in bovine embryos. Other factors that may affect the viability of embryos after electroporation are the thickness of the zona pellucida and developmental stage of the embryos. The thickness of the zona pellucida is reduced by expansion of the blastocyst. A previous study in mouse embryos demonstrated that the thinner the zona pellucida, the more easily a macromolecule can be introduced into embryos under identical electric pulses, although embryo viability decreases after electroporation [13]. Moreover, our previous study using in vitro-derived porcine 1-cell zygotes showed that sensitivity to electroporation is affected by the zygote stage [15]. The developmental stage of bovine embryos could also affect their viability after electroporation. To our knowledge, the viability of embryos of various developmental stages after electroporation has not been investigated in cows. All these factors should be considered in order to maintain the viability of embryos after electroporation procedures.

In conclusion, electroporation successfully introduced exogenous molecules into in vivo-derived bovine blastocysts without loss of viability. Moreover, we demonstrated that the status of the zona pellucida may be associated with the quality of blastocysts after electroporation in in vivo-derived bovine blastocysts. To date, there are few studies of electroporation of blastocysts in domestic animals. Additional studies are warranted to identify the factors that affect the outcome of electroporation in various animal species including cows, to further improve this technique for efficient introduction of molecules into embryos.

\section{Methods}

\section{Animals}

All animal experiments were performed in accordance with the Guidelines for Animal Experiments of Tokushima University. This study was approved by the Institutional Animal Care and Use Committee of Tokushima University (approval number: T2019-24).

\section{Blastocyst collection}

Holstein cows $(n=5), 4-8$ years of age, were superovulated with follicle-stimulating hormone (FSH, Kyoritsu Seiyaku, Tokyo, Japan) at a dose of 30 A.U. decreasing over 5 days $(6,6 / 4,4 / 3,3 / 2,2)$. A controlled intravaginal drug releasing device (CIDR; Eazibreed $\mathrm{R}$; 
Livestock Improvement Association of Japan, Tokyo, Japan) was inserted into the vagina of each cow with intramuscular injection of $2 \mathrm{mg}$ estradiol-benzoate (Ovahormon $\mathbb{R}$; ASUKA Animal Health, Tokyo, Japan) $96 \mathrm{~h}$ before the first FSH injection. Luteolysis was induced with one injection of $0.75 \mathrm{mg}$ prostaglandin (PG) F2 $\alpha$ analogue (Cloprostenol; Estrumate ${ }^{\circledR}$, Intervet, Tokyo, Japan) given at the time of the seventh FSH injection. The CIDR was withdrawn at the eighth FSH injection and $200 \mu \mathrm{g}$ gonadotropin-releasing hormone $(\mathrm{GnRH})$ analogue (Fertirelin acetate; Spornen ${ }^{\circledR}$, Kyoritsu Seiyaku) was injected $24 \mathrm{~h}$ after CIDR withdrawal. Cows were inseminated twice with $0.5 \mathrm{ml}$ frozen-thawed semen $\left(1 \times 10^{7}\right.$ cells $\left./ \mathrm{ml}\right)$, about 12 and $24 \mathrm{~h}$ after the Fertirelin acetate injection. Embryos were collected non-surgically 8 days after the first insemination, according to procedures described previously [25]. The embryos were examined microscopically for morphological quality and developmental stage as previously described [26]. The embryos were graded for quality: Grade $\mathrm{A}=$ excellent, Grade $\mathrm{B}=$ good, Grade $\mathrm{C}=$ fair, Grade $\mathrm{D}=$ poor, and Grade $\mathrm{E}=$ degenerate. Only Grade A embryos $(n=61)$ were used in this study. The embryos were placed in Dulbecco's phosphate-buffered saline (DPBS) with magnesium and calcium (Gibco/Invitrogen, Carlsbad, CA, USA) supplemented with $20 \%$ fetal bovine serum (FBS; Thermo Fisher Scientific, Waltham, MA, USA), and were transported within $2 \mathrm{~h}$ to the laboratory at $37.5^{\circ} \mathrm{C}$.

\section{Incubation of blastocysts}

The blastocysts were washed with culture medium consisting of tissue culture medium 199 with Earle's salts (TCM 199; Gibco/ Invitrogen) supplemented with 20\% FBS (Thermo Fisher Scientific), $50 \mu \mathrm{M}$ chlorogenic acid (Sigma-Aldrich, St. Louis, MO, USA), $1 \times$ insulin-transferrin-selenium supplement (ITS, Sigma-Aldrich) and 50 $\mu \mathrm{g} / \mathrm{ml}$ gentamicin (Sigma-Aldrich). The blastocysts were subsequently incubated individually in $40 \mu \mathrm{l}$ of culture medium under a layer of mineral oil in an ART Culture Dish 25 (NIPRO, Osaka, Japan) until electroporation and for $24 \mathrm{~h}$ after electroporation. The incubation of the blastocysts was conducted at $38.5^{\circ} \mathrm{C}$ in a humidified incubator containing $5 \% \mathrm{CO}_{2}$ and $5 \% \mathrm{O}_{2}$

\section{Electroporation}

Electroporation was performed as described previously [15]. Briefly, the electrode (LF501PT1-20; BEX, Tokyo, Japan) was connected to a CUY21EDIT II electroporator (BEX) and set under a stereoscopic microscope. The blastocysts were washed with Opti-MEM I solution (Gibco/Invitrogen) and placed in a line in the electrode gap, in a chamber slide filled with $10 \mu \mathrm{l}$ Opti-MEM I solution containing oligonucleotide labeled with FAM at the $5^{\prime}$ and 3 ' ends, synthesized by Eurofins Genomics KK (Tokyo, Japan): 5'-[FAM]-ACGACGCGACTAGCGCACCGATACGTCGT-[FAM]-3'. The sequence of the oligonucleotide was confirmed by database analysis to have no homology with any bovine mRNA.

\section{Statistical analysis}

The diameters of blastocyst before and after electroporation were evaluated using a paired t-test for each group. The analysis was performed in StatView (Abacus Concepts, Berkeley, CA, USA). P $<0.05$ was considered statistically significant.

\section{Acknowledgments}

We thank the staff of the Tokushima Prefectural Livestock Research Institute for assistance with animal management. This study was supported in part by the "Funds for the Development of Human Resources in Science and Technology" under MEXT, through the "Home for Innovative Researchers and Academic Knowledge Users (HIRAKU)" consortium, and Agriculture, Forestry and Fisheries Open Innovation Promotion Program of Tokushima Prefecture. We acknowledge Tokushima University for their financial support of the Research Clusters program of Tokushima University (No. 1701001).

\section{References}

1. Graf A, Krebs S, Heininen-Brown M, Zakhartchenko V, Blum H, Wolf E. Genome activation in bovine embryos: review of the literature and new insights from RNA sequencing experiments. Anim Reprod Sci 2014; 149: 46-58. [Medline] [CrossRef]

2. Delcuve GP, Rastegar M, Davie JR. Epigenetic control. J Cell Physiol 2009; 219 243-250. [Medline] [CrossRef]

3. Urrego R, Bernal-Ulloa SM, Chavarría NA, Herrera-Puerta E, Lucas-Hahn A, Herrmann D, Winkler S, Pache D, Niemann H, Rodriguez-Osorio N. Satellite DNA methylation status and expression of selected genes in Bos indicus blastocysts produced in vivo and in vitro. Zygote 2017; 25: 131-140. [Medline] [CrossRef]

4. Yamagata K, Okada Y. Understanding paternal genome demethylation through live-cell imaging and siRNA. Cell Mol Life Sci 2011; 68: 1669-1679. [Medline] [CrossRef]

5. Eisen JS, Smith JC. Controlling morpholino experiments: don't stop making antisense. Development 2008; 135: 1735-1743. [Medline] [CrossRef]

6. Chen M, Yang Y, Krueger CJ, Chen AK. Optimizing molecular beacons for intracellular analysis of RNA. Methods Mol Biol 2018; 1649: 243-257. [Medline] [CrossRef]

7. Meacham JM, Durvasula K, Degertekin FL, Fedorov AG. Physical methods for intracellular delivery: practical aspects from laboratory use to industrial-scale processing. $J$ Lab Autom 2014; 19: 1-18. [Medline] [CrossRef]

8. Sato M, Ohtsuka M, Watanabe S, Gurumurthy CB. Nucleic acids delivery methods for genome editing in zygotes and embryos: the old, the new, and the old-new. Biol Direct 2016; 11: 16. [Medline] [CrossRef]

9. Galli C, Perota A, Brunetti D, Lagutina I, Lazzari G, Lucchini F. Genetic engineering including superseding microinjection: new ways to make GM pigs. Xenotransplantation 2010; 17: 397-410. [Medline] [CrossRef]

10. Baron S, Poast J, Rizzo D, McFarland E, Kieff E. Electroporation of antibodies, DNA, and other macromolecules into cells: a highly efficient method. J Immunol Methods 2000; 242: 115-126. [Medline] [CrossRef]

11. Khine M, Lau A, Ionescu-Zanetti C, Seo J, Lee LP. A single cell electroporation chip Lab Chip 2005; 5: 38-43. [Medline] [CrossRef]

12. Grabarek JB, Plusa B, Glover DM, Zernicka-Goetz M. Efficient delivery of dsRNA into zona-enclosed mouse oocytes and preimplantation embryos by electroporation. Genesis 2002; 32: 269-276. [Medline] [CrossRef]

13. Peng $\mathbf{H}, \mathbf{W u} \mathbf{Y}$, Zhang Y. Efficient delivery of DNA and morpholinos into mouse preimplantation embryos by electroporation. PLoS One 2012; 7: e43748. [Medline] [CrossRef]

14. Kaneko T, Sakuma T, Yamamoto T, Mashimo T. Simple knockout by electroporation of engineered endonucleases into intact rat embryos. Sci Rep 2014; 4: 6382. [Medline] [CrossRef]

15. Tanihara F, Takemoto T, Kitagawa E, Rao S, Do LT, Onishi A, Yamashita Y, Kosugi C, Suzuki H, Sembon S, Suzuki S, Nakai M, Hashimoto M, Yasue A, Matsuhisa M, Noji S, Fujimura T, Fuchimoto D, Otoi T. Somatic cell reprogramming-free generation of genetically modified pigs. Sci $A d v$ 2016; 2: e1600803. [Medline] [CrossRef]

16. Hashimoto M, Takemoto T. Electroporation enables the efficient mRNA delivery into the mouse zygotes and facilitates CRISPR/Cas9-based genome editing. Sci Rep 2015; 5: 11315. [Medline] [CrossRef]

17. Holm $\mathbf{P}$, Callesen $\mathbf{H}$. In vivo versus in vitro produced bovine ova: similarities and differences relevant for practical application. Reprod Nutr Dev 1998; 38: 579-594. [Medline] [CrossRef]

18. Pollard JW, Leibo SP. Chilling sensitivity of mammalian embryos. Theriogenology 1994; 41: 101-106. [CrossRef]

19. Curnow EC, Gunn IM, Trounson AO. Electrofusion of two-cell bovine embryos for the production of tetraploid blastocysts in vitro. Mol Reprod Dev 2000; 56: 372-377. [Medline] [CrossRef] 
20. Kubiak JZ, Tarkowski AK. Electrofusion of mouse blastomeres. Exp Cell Res 1985; 157: 561-566. [Medline] [CrossRef]

21. Taniguchi T, Cheong HT, Kanagawa H. Fusion and development rates of single blastomere pairs of mouse two- and four-cell embryos using the electrofusion method. Theriogenology 1991; 36: 645-654. [Medline] [CrossRef]

22. Nishio K, Tanihara F, Nguyen TV, Kunihara T, Nii M, Hirata M, Takemoto T, Otoi T. Effects of voltage strength during electroporation on the development and quality of in vitro-produced porcine embryos. Reprod Domest Anim 2018; 53: 313-318. [Medline] [CrossRef]

23. Ikeda S, Sugimoto M, Kume S. Lipofection of siRNA into bovine 8-16-cell stage embryos using zona removal and the well-of-the-well culture system. J Reprod Dev 2018; 64:
199-202. [Medline] [CrossRef]

24. Ovcharenko D, Jarvis R, Hunicke-Smith S, Kelnar K, Brown D. High-throughput RNAi screening in vitro: from cell lines to primary cells. RNA 2005; 11: 985-993. [Medline] [CrossRef]

25. Suzuki T, Suzuki M, Shimohira I, Fujiyama M. An automatic flushing instrument for bovine embryo. Japan Journal of Animal Reproduction 1984; 30: 194-196 (in Japanese) [CrossRef]

26. Callesen H, Løvendahl P, Bak A, Greve T. Factors affecting the developmental stage of embryos recovered on day 7 from superovulated dairy cattle. J Anim Sci 1995; 73: 1539-1543. [Medline] [CrossRef] 